\title{
SALURAN DISTRIBUSI DAN PENETAPAN HARGA SAYURAN PADA PEDAGANG BESAR DAN PEDAGANG PENGECER KOTA BANDA ACEH
}

\author{
(Distribution Channel And Determination Of Vegetable Prices In Wholesaller And Retailers \\ In Banda Aceh City)
}

\author{
Dani Gunawan ${ }^{1}$, Ismayani ${ }^{1}$, Romano $^{1 *}$ \\ ${ }^{1}$ Program Studi Agribisnis, Fakultas Pertanian, Universitas Syiah Kuala
}

\begin{abstract}
Abstrak,Saluran distribusi adalah lembaga-lembaga distributor atau lembaga-lembaga penyalur yang mempunyai kegiatan untuk menyalurkan atau menyampaikan barang-barang atau jasa-jasa dari produsen ke konsumen. Penelitian ini bertujuan untuk mengetahui ketergantungan penetapan harga sayuran terhadap saluran distribusi pada pedagang besar dan pedagang pengecer kota Banda Aceh. Metode yang digunakan dalam penelitian ini adalah metode survey, disebabkan banyaknya pedagang maka penelitian ini dilakukan dengan metode pengambilan sampel yang mewakili populasi dan dilakukan sumber informasi yang dapat menggambarkan keadaan masyarakat didaerah penelitian. Hasil dalam penelitian ini adalah (1) $\mathrm{X}^{2}$ hitung $<\mathrm{X}^{2}$ tabel dan $\alpha \geq \mathrm{p}_{\text {value }}$ yang menunjukkan $\mathrm{H}_{\mathrm{a}}$ diterima dan $\mathrm{H}_{0}$ ditolak, artinya saluran distribusi berpengaruh tidak nyata terhadap penetapan harga. (2) Contigency coefficient $(\mathrm{r})$ memiliki hasil 0,707 yang berarti saluran distribusi memiliki keterkaitan yang kuat dengan penetapan harga sayuran pada pedagang besar dan pedagang pengecer di Kota Banda Aceh. (3) Biaya pemasaran pedagang besar lebih besar dibandingkan biaya pemasaran pedagang pengecer, yaitu masingmasing Rp.46.307.200/tahun dan Rp.41.250.000/tahun.
\end{abstract}

\section{Kata Kunci : Saluran Distribusi, Pedagang Besar, Pedagang Pengecer, Penetapan Harga, dan Contigency Coefficient}

\begin{abstract}
Abstact, Distribution channels are distributor institutions or channeling institutions that have activities to distribute or deliver goods or services from producers to consumers. This study aims to determine the dependence of vegetable pricing on distribution channels on wholesalers and retailers in the city of Banda Aceh. The method used in this study is a survey method, due to the large number of traders so this study was conducted with a sampling method that represents the population and carried out information sources that can describe the condition of the community in the research area. The results in this study are (1) X2count $<\mathrm{X} 2$ table and $\alpha \geq$ pvalue $\neg$ which shows that Ha is accepted and H0 is rejected, meaning that the distribution channel has no significant effect on pricing. (2) Contigency coefficient (r) has a result of 0.707 which means that the distribution channel has a strong connection with the determination of vegetable prices at wholesalers and retailers in the city of Banda Aceh. (3) The marketing costs of wholesalers are greater than the marketing costs of retailers, namely Rp.46,307,200 / year and Rp.41,250,000 / year.
\end{abstract}

Keywords: Distribution Channels, Wholesalers, Retailers, Pricing, and Contingency Coefficien

\section{PENDAHULUAN}

Sayuran merupakan salah satu bagian dari tanaman holtikutura yaitu hasilnya dapat di peroleh dalam bentuk sayuran daun, sayuran buah, sayuran umbi akar, sayuran bunga dan sayuran buahbuahan. Sayuran dalam kehidupan sehari-hari memegang peranan yang cukup penting. Dengan membiasakan makanan sayuran berarti sebagian dari kebutuhan tubuh terhadap zat-zat makanan terpenuhi, karena sayuran merupakan sumber vitamin, mineral, protein nabati dan lemak yang sangat penting bagi kesehatan. Adapun data harga pemasaran sayuran dapat dilihat pada Tabel 1.

*Corresponding author: romanos_agri@gmail.com 
Tabel 1. Harga Beli dan Harga Jual Sayuran pada Pedagang Besar dan Pedagang Pengecer Kota Banda Aceh

\begin{tabular}{llrrrr}
\hline \multirow{2}{*}{ No. } & \multirow{2}{*}{ Jenis Sayuran } & \multicolumn{2}{c}{ Pedagang Besar } & \multicolumn{2}{c}{ Pedagang Pengecer } \\
\cline { 3 - 6 } & & Beli $(\mathbf{R p} / \mathbf{K g})$ & Jual $(\mathbf{R p} / \mathbf{K g})$ & Beli $(\mathbf{R p} / \mathbf{K g})$ & Jual (Rp/Kg) \\
\hline 1. & Bawang Merah & 14.000 & 30.000 & 30.000 & 32.000 \\
2. & Cabai Merah & 65.500 & 80.000 & 80.000 & 100.000 \\
3. & Tomat & 6.000 & 11.000 & 11.000 & 12.000 \\
\hline
\end{tabular}

Sumber : Data Primer (Diolah) 2017

Aceh merupakan salah satu produsen sayuran. Dimana banyak jenis sayuran yang dihasilkan seperti kentang, cabai merah, bawang merah, tomat, sawi dan sebagainya. Sayursayuran tersebut didatangkan dari berbagai daerah yang ada di aceh. Tanaman sayuran merupakan salah satu usaha tani yang banyak diminati oleh penduduk pendesaan selain menanam padi. Sayuran banyak digemari dan dikonsumsi oleh semua kalangan baik masyarakat kelas bawah maupun kelas atas, karena pemenuhan kebutuhan sayurandisamping mengandung zat gizi tinggi juga harga yang terjangkau oleh semua kalangan.

Pasar Lambaro berada di Desa Lambaro Kecamatan Blang Bintang Kabupaten Aceh Besar Provinsi Nanggroe Aceh Darussalam Indonesia.Pasar ini merupakan pasar induk di kawasan aceh besar yang memiliki berbagai komoditi sayuran yang juga merupakan pemasok bagi pedagang - pedagang eceran yang ada di Banda aceh, salah satunya pasar peunayong.

Pasar Peunayong berdiri pada tahun 1968 yang berada di pinggiran sungai Aceh (Krueng Aceh) Kota Banda Aceh. Pasar ini masuk dalam Kelurahan Peunayong Kecamatan Kuta Alam Kota Banda Aceh. Pada tahun 2004, bencana tsunami memporak porandakan pasar sehingga rata dengan tanah. Namun, kondisi ini tidak berlangsung lama, dimana dalam masa rekonstruksi pada awal tahun 2005, Pemko Banda Aceh bekerjasama dengan CHF (Community Habitat Finance), CRS (Catholic Relief Services) dan ARC (American Red Cross) membangun kembali komplek Pasar Peunayong menjadi tiga gedung bertingkat, yang dikelompokkan berdasarkan bahan pangan. Pasar Peunayong merupakan pasar tradisional terbesar di Kota Banda Aceh yang mempunyai nilai strategis dan prospek di masa yang akan datang. Pasar ini adalah merupakan salah satu pusat pasar dan sebagai distribusi barang-barang terhadap pasar tradisionaldi Kota Banda Aceh. Berdasarkan latar belakang tersebut peneliti merasa tertarik untuk meneliti "Saluran Distribusi Dan Penetapan Harga Sayuran Pada Pedagang Besar Dan Pedagang Pengecer Kota Banda Aceh”. Tujuan dari penelitian ini adalah untuk mengetahui ketergantungan penetapan harga terhadap saluran distribusi pedagang sayurkota Banda Aceh.

\section{Tempat dan Waktu Penelitian}

\section{METODE PENELITIAN}

Penelitian ini penelitian ini dilakukan di pasar Lambaro dan pasar Peunayong Kota Banda Aceh. Penentuan lokasi dilakukan secara sengaja dengan pertimbangan bahwa daerah ini mempunyai prospek masa depan yang cerah dalam pemasokan sayuran untuk kebutuhan Kota Banda Aceh.

\section{Objek dan Ruang Lingkup}

Objek penelitian yang digunakan adalah pedagang sayur. Ruang lingkup penelitian ini hanya dibatasi pada distribusi pedagang sayur di pasar Lambaro dan pasar Peunayong Kota Banda Aceh..

\section{Teknik Penentuan Sampel}


Populasi dalam penelitian ini adalah pedagang besar dan pedagang pengecer yang ada di pasar peunayong, sedangkan sampel adalah pedagang yang mewakili populasi pada masing masing kriteria ( pedagang besar dan pedagang pengecer ).

Teknik Penentuan sampel pada penelitian ini menggunakan metode Snowball Sampling untuk jumlah pedagang besar sebesar 20 persen karena jumlah sampel pada pedagang besar hanya 5 sampel sedangkan untuk jumlah pedagang pengecer sebesar 10 persen.

\section{Batasan Variabel dan Metode Analisis \\ Batasan Variabel}

Variabel yang digunakan dalam penelitian ini yaitu pedagang sayuran, saluran distribusi dan penetapan harga antara pedagang besar dan pedagang pengecer.

\section{Metode Analisis}

\section{Uji Kuadrat Chi Square}

Data hasil penelitian yang dikumpulkan di lapangan akan diolah dan ditabulasikan selanjutnya dipindahkan kedalam bentuk tabel koefisien kontigensi sesuai dengan kebutuhan analisis kesesuaian penetapan harga menurut saluran distribusi.

Untuk menguji hipotesis yang telah diturunkan maka digunakan uji kuadrat Chi Square kebijakan penetapan harga untuk pedagang besar dan pedagang pengecer dengan rumus sebagai berikut :

$$
x^{2}=\sum \frac{(0-E)^{2}}{E}
$$

Yang didistribusikan dengan degree of freedom = k-1

Dimana :

$x^{2}=$ Nilai Chi Square

$E=$ Frekuensi yang diharapkan

$O=$ Frekuensi yang diobservasi

Tabel 2. Kontigensi Penetapan Harga Komoditi Sayuran pada Pedagang Besar dan Pedagang Pengecer

\section{Penetapan Harga}

\section{Saluran}

Volume Beli (Kg) Volume Jual (kg) Harga Beli (Rp/Kg) Harga Jual (Rp/Kg)

\begin{tabular}{|c|c|c|c|c|}
\hline Pedagang Besar & $\mathrm{O} 11 / \mathrm{E} 12$ & $\mathrm{O} 12 / \mathrm{E} 12$ & O13/E13 & O14/E14 \\
\hline Pedagang Pengecer & $\mathrm{O} 21 / \mathrm{E} 21$ & $\mathrm{O} 22 / \mathrm{E} 22$ & $\mathrm{O} 23 / \mathrm{E} 23$ & $\mathrm{O} 24 / \mathrm{E} 24$ \\
\hline
\end{tabular}

Adapun kegunaan Koefisien Kontigensi ini untuk mengukur derajat hubungan, asosiasi atau dependensi dari klasifikasi-klasifikasi dalam tabel Kontigensi. Derajat hubungan disini menunjukkan ada korelasi atau tidak antara kolom dan baris tabel kontigensi dan apakah terdapat hubungan tersebut kuat atau tidak kuat.

Adapun interpretasi $\mathrm{r}$ berkisar antara $0-1$ dengan kriteria sebagai berikut:

$0 \quad=\quad$ tidak ada korelasi antar variabel

$>0-0,25=\quad$ korelasi sangat lemah

$>0,25-0,5 \quad=$ korelasi cukup

$>0,5-0,75=$ korelasi kuat

$>0,75-0,99=$ korelasi sangat kuat

$1 \quad=$ korelasi sempurna

Rumus koefisien kontigensi adalah : 
$x^{2}=\sum_{\mathrm{i}} \quad \sum_{\mathrm{j}} \frac{\left(\mathrm{c}_{\mathrm{ij}}-e_{\mathrm{j}}\right)}{e_{\mathrm{ij}}}$

Dimana :

$\mathrm{X}^{2}=$ Nilai chi-Square

$\mathrm{e}_{\mathrm{i}}=$ Frekuensiharapan

$\mathrm{c}_{1}=$ Frekuensi yang diamati

Hipotesis yang diformulasikan yaitu :

Tolak $\mathrm{H}_{0}$, terima $\mathrm{H}_{\mathrm{a}}$, jika:

$\mathrm{X}_{\text {hitung }}^{2}<\mathrm{X}_{\text {tabel, }}^{2} \alpha=0,05, \mathrm{df}=(\mathrm{r}-1)(\mathrm{k}-1)=(2-1)(2-1)=1$, dimana $\mathrm{r}=$ baris dan $\mathrm{k}=$ kolom

Tolak $\mathrm{H}_{0}$, terima $\mathrm{H}_{\mathrm{a}}$, jika:

$\mathrm{X}^{2}$ hitung $\geq \mathrm{X}^{2}$ tabel, $\alpha=0,05 \mathrm{df}=1$

Penarikan kesimpulan dilakukan dengan metode analisis sebagai berikut :

$\mathrm{H}_{\mathrm{a}}=$ artinya saluran distribusi berkaitan dengan penetapan harga sayuran pada pedagang besar dan pedagang pengecer di kota Banda Aceh.

$\mathrm{H}_{0}=$ artinya saluran distribusi tidak berkaitan terhadap penetapan harga pada pedagang besar dan pedagang pengecer di kota Banda Aceh.

\section{Identitas Koresponden}

\section{HASIL DAN PEMBAHASAN}

Berdasarkan hasil penelitian saluran distribusi dan penetapan harga sayuran pada pedagang besar dan pedagang pengecer di Kota Banda Aceh, maka didapatkan identitas koresponden yang terdiri dari umur, pekerjaan, jenis kelamin, jumlah tanggungan, dan pendapatan per bulan

Umur

Berdasarkan hasil penelitian yang dilakukan menggunakan wawancara secara kuesioner, maka didapatkan identitas koresponden berdasarkan umur seperti pada Tabel 3 berikut ini: Tabel 3. Jumlah Responden Berdasarkan Umur

\begin{tabular}{cccc}
\hline No. & $\begin{array}{c}\text { Umur } \\
\text { (Tahun) }\end{array}$ & $\begin{array}{c}\text { Jumlah Koresponden } \\
\text { (Orang) }\end{array}$ & $\begin{array}{c}\text { Persentase } \\
(\%)\end{array}$ \\
\hline 1. & 36 & 1 & 4 \\
2. & 38 & 2 & 8 \\
3. & 41 & 1 & 4 \\
4. & 42 & 2 & 8 \\
5. & 43 & 2 & 8 \\
6. & 44 & 1 & 4 \\
7. & 45 & 1 & 4 \\
8. & 46 & 2 & 8 \\
9. & 47 & 1 & 4 \\
10. & 48 & 8 & 32 \\
11. & 49 & 1 & 4 \\
\hline
\end{tabular}




\begin{tabular}{cccc}
\hline No. & $\begin{array}{c}\text { Umur } \\
\text { (Tahun) }\end{array}$ & $\begin{array}{c}\text { Jumlah Koresponden } \\
\text { (Orang) }\end{array}$ & $\begin{array}{c}\text { Persentase } \\
(\boldsymbol{\%})\end{array}$ \\
\hline 12. & 50 & 3 & 12 \\
Total & & 25 & $\mathbf{1 0 0}$ \\
\hline
\end{tabular}

Sumber: Data Primer, 2017 (Diolah)

Berdasarkan Tabel 3 didapatkan bahwa sebesar $32 \%$ para pedagang sayuran di Kota Banda Aceh berumur 48 tahun, sisanya berada pada usia 36 - 47 tahun dan $49-50$ tahun. Hal ini sesuai dengan pendapat Mantra (2004) yang menyatakan bahwa usia produktif secara ekonomi berada pada usia $15-64$ tahun.

\section{Jenis Kelamin}

Berdasarkan hasil penelitian yang di lakukan menggunakan wawancara secara kuisioner, maka didapatkan rata - rata jenis kelamin pada pedagang sayuran kota Banda Aceh seperti pada Tabel 4 berikut :

Tabel 4. Jumlah Responden Berdasarkan Jenis Kelamin

\begin{tabular}{clcccc}
\hline No. & Jenis Kelamin & $\begin{array}{c}\text { Pedagang Besar } \\
\text { (Orang) }\end{array}$ & $\begin{array}{c}\text { Pedagang Pengecer } \\
\text { (Orang) }\end{array}$ & $\begin{array}{c}\text { Jumlah } \\
\text { (Orang) }\end{array}$ & $\begin{array}{c}\text { Persentase } \\
(\%)\end{array}$ \\
\hline 1. & Laki & 5 & 19 & 24 & $96 \%$ \\
$2 . \quad$ Perempuan & 0 & 1 & 1 & $4 \%$ \\
Total & $\mathbf{5}$ & $\mathbf{2 0}$ & $\mathbf{2 5}$ & $\mathbf{1 0 0 \%}$ \\
\hline
\end{tabular}

Sumber : Data Primer, 2017 (Diolah)

Berdasarkan tabel 4 didapatkan persentase jenis kelamin pada pedagang sayuran di kota Banda aceh terdapat $96 \%$ untuk jenis kelamin laki - laki sedangkan $4 \%$ untuk jenis kelamin perempuan, yaitu 19 orang pedagang yang berjenis kelamin laki - laki dan hanya 1 orang berjenis kelamin perempuan, hal ini dikarenakan umumnya para laki - laki memiliki tanggungan untuk menghidupi sanak keluarga sedangkan untuk perempuan dikarenakan sudah menjadi kepala keluarga untuk bertanggung jawab dikeluarganya.

\section{Pendidikan Terakhir}

Berdasarkan hasil penelitian yang di lakukan melakukan wawancara secara kuisioner, maka didapatkan rata - rata pendidikan terakhir pedagang besar dan pedagang pengecer di kota Banda Aceh seperti pada Tabel 5 seperti berikut :

Tabel 5. Jumlah Responden Berdasarkan Pendidikan Terakhir

\begin{tabular}{lrcccc}
\hline No. & Pendidikan Terakhir & $\begin{array}{c}\text { Pedagang Besar } \\
\text { (orang) }\end{array}$ & $\begin{array}{c}\text { Pedagang Pengecer } \\
\text { (orang) }\end{array}$ & $\begin{array}{c}\text { Jumlah } \\
\text { (orang) }\end{array}$ & $\begin{array}{c}\text { Persentase } \\
(\boldsymbol{\%})\end{array}$ \\
\hline 1. & SLTP/SMP & 0 & 7 & 7 & $28 \%$ \\
2. & SLTA/SMA & 5 & 13 & 18 & $72 \%$ \\
Total & & $\mathbf{5}$ & $\mathbf{2 0}$ & $\mathbf{2 5}$ & $\mathbf{1 0 0} \%$ \\
\hline
\end{tabular}

Sumber : Data Primer (Diolah) 2017

Berdasarkan tabel 5 didapatkan persentase jumlah rata - rata pendidikan terakhir pada pedagang sayuran dapat dilihat bahwa untuk pedagang besar dan pedagang pengecer sebanyak $28 \%$ yang berpendidikan SMP yaitu hanya pada pedagang pengecer sebanyak 7 orang, sedangkan untuk yang berpendidikan SMA sebesar $72 \%$ dengan jumlah 5 orang pada pedagang besar dan 13 orang pada pedagang pengecer. 


\section{Jumlah Tanggungan}

Berdasarkan hasil penelitian yang di lakukan melakukan wawancara secara kuisioner, maka didapatkan rata - rata jumlah tanggungan pedangan besar dan pedagang pengecer di kota Banda Aceh seperti pada Tabel 6 seperti berikut :

Tabel 6. Jumlah Responden Berdasarkan Jumlah Tanggungan

\begin{tabular}{lrcccc}
\hline No. & Jumlah Tanggungan & $\begin{array}{c}\text { Pedagang Besar } \\
\text { (orang) }\end{array}$ & $\begin{array}{c}\text { Pedagang Pengecer } \\
\text { (orang) }\end{array}$ & $\begin{array}{c}\text { Jumlah } \\
\text { (orang) }\end{array}$ & $\begin{array}{c}\text { Persentase } \\
(\boldsymbol{\%})\end{array}$ \\
\hline 1. & $1-2$ Orang & 0 & 5 & 5 & $20 \%$ \\
2. & $2-5$ Orang & 2 & 7 & 12 & $48 \%$ \\
3. & > 5 Orang & 2 & 8 & 8 & $32 \%$ \\
Total & & $\mathbf{4}$ & $\mathbf{2 1}$ & $\mathbf{2 5}$ & $\mathbf{1 0 0 \%}$ \\
\hline
\end{tabular}

Sumber : Data Primer, 2017 (Diolah)

Berdasarkan Tabel 6 didapatkan persentase jumlah tanggungan pada pedagang sayuran di kota banda aceh sebesar 20\% memiki jumlah tanggungan $1-2$ orang, $48 \%$ untuk jumlah tanggungan $2-5$ orang dan sebesar $32 \%$ memiliki jumlah tanggungan $>5$ orang. Hal ini sesuai dengan standar perhitungan besarnya jumlah tanggungan keluarga menurut Hasan (1986), yaitu suatu keluarga dikatakan sebagai keluarga besar apabila jumlah tanggungannya lebih dari 3 orang, sedangkan jika tanggungan keluarga kurang dari 3 orang maka keluarga tersebut termasuk ke dalam kategori keluarga kecil.

\section{Pendapatan Per Bulan}

Berdasarkan hasil penelitian yang dilakukan melakukan wawancara secara kuisioner,maka didapatkan rata - rata pendapatan perbulan pedagang besar dan pedagang pengecer di kota Banda aceh seperti pada tabel 7 berikut :

Tabel 7. Jumlah Responden Berdasarkan Pendapatan per Bulan

\begin{tabular}{crcr}
\hline No. & Klasifikasi Pendapatan (Rp/Bulan) & Frekuensi & Persentase (\%) \\
\hline 1. & $<5.000 .000$ (Kecil) & 10 & $40 \%$ \\
2. & $6.000 .000-15.000 .000$ (Sedang) & 10 & $40 \%$ \\
3. & $>15.000 .000$ (Besar) & 5 & $20 \%$ \\
Total & & & $100 \%$ \\
\hline
\end{tabular}

Sumber : Data Primer, 2017 (Diolah)

Berdasarkan Tabel 7 didapatkan bahwa pendapatan terbanyak perbulan rata - rata yang di peroleh oleh pedagang pengecer sebesar $40 \%$ yaitu 10 orang dengah jumlah pendapatan perbulan Rp 2.500.000 , sedangkan untuk pendapatan yang paling sedikit perbulan rata - rata yang yg di peroleh oleh pedagang pengecer sebesar $4 \%$ yaitu 1 orang dengan jumlah pendapatan perbulan Rp. 2.400.000.

Sedangkan untuk pedagang besar pendapatan terbanyak perbulan sebesar $8 \%$ yaitu 4 orang dengan jumlah pendapatan Rp. 35.000.000 - Rp. 40.000.000, sedangkan untuk pendapatan paling sedikit hanya $4 \%$ yaitu 1 orang dengan jumlah pendapatan perbulan Rp. 45.000.000.

\section{Biaya Pemasaran}

Setiap saluran distribusi tidak terlepas dari biaya pemasaran. Biaya pemasaran dilakukan oleh para pedagang untuk bisa menyalurkan barang kepada para konsumen. Adapun biaya pemasaran pada penelitian ini terdiri dari ongkos, upah/gaji, sewa tempat, restribusi, serta 
kemasan. Untuk setiap saluran distribusi memiliki biaya pemasaran yang berbeda yang dapat dilihat pada Tabel 8 berikut ini.

Tabel 8. Rata-rata Biaya Pemasaran pada Saluran Distribusi

\begin{tabular}{cccc}
\hline \multirow{2}{*}{ No. } & \multirow{2}{*}{ Biaya Pemasaran } & \multicolumn{2}{c}{ Saluran Distribusi } \\
\cline { 3 - 4 } & & Pedagang Besar (Rp/tahun) & Pedagang Pengecer (Rp/tahun) \\
\hline 1. & Ongkos & 3.600 .000 & 3.600 .000 \\
2. & Upah/gaji & 16.320 .000 & 13.920 .000 \\
3. & Sewa tempat & 25.000 .000 & 22.350 .000 \\
\hline 4. & Restribusi & 720.000 & 720.000 \\
5. & Kemasan & 667.200 & 660.000 \\
& Total & $\mathbf{4 6 . 3 0 7 . 2 0 0}$ & $\mathbf{4 1 . 2 5 0 . 0 0 0}$ \\
\hline
\end{tabular}

Sumber: Data Primer, 2017 (Diolah)

Berdasarkan Tabel 8 dapat dilihat bahwa pada saluran distribusi rata-rata memiliki pengeluaran untuk ongkos dan restribusi yang sama, yaitu Rp.3.600.000/tahun dan Rp.720.000/tahun. Sedangkan, untuk upah/gaji pedagang besar memiliki biaya pemasaran yang lebih besar dibandingkan dengan pedagang pengecer. Hal tersebut dikarenakan para pedagang besar memiliki para pekerja yang harus diberikan upah, sehingga biaya untuk upah/gaji pada pedagang besar lebih besar, yaitu dengan rata-rata Rp.16.320.000/tahun dan pedagang kecil Rp.13.920.000/tahun.

Untuk sewa tempat, pedagang besar memiliki biaya yang lebih besar dikarenakan para pedagang besar harus menyewa toko untuk melakukan proses jual beli. Selanjutnya untuk kemasan, para pedagang besar juga memiliki nilai rata-rata yang lebih besar dibandingkan pedagang pengecer, masing - masing Rp.667.200/tahun dan Rp.660.000/tahun. Hal tersebut terjadi karena pedagang besar biasanya menyetok kemasan lebih banyak dari pedagang pengecer.

Jadi berdasarkan Tabel 8 dan penjelasan sebelumnya dapat disimpulkan bahwa pada saluran distribusi, biaya pemasaran pedagang besar lebih besar dibandingkan biaya pemasaran pedagang pengecer, yaitu masing-masing Rp.46.307.200/tahun dan Rp.41.250.000/tahun. Hal tersebut terjadi karena para pedagang besar lebih membutuhkan tempat berjualan yang besar, upah karyawan, dan kemasan yang banyak untuk melakukan proses jual beli dibandingkan dengan pedagang pengecer.

\section{Koefision Kontigensi Saluran Distribusi Dan Penetapan Harga Sayuran}

Koefision kontigensi adalah metode yang digunakan unutk mengukur keeratan hubungan (asiosiasi atau korelasi) antara 2 variabel yang keduanya bertipe nominal (kategorik).

Tabel 9. Kontigensi Saluran Distribusi dan Penetapan Harga Bawang Merah pada Pedagang Besar dan Pedagang Pengecer

\begin{tabular}{|c|c|c|c|c|}
\hline \multirow[b]{2}{*}{ Saluran Distribusi } & \multicolumn{4}{|c|}{ Penetapan Harga } \\
\hline & $\begin{array}{c}\text { Volume Jual } \\
(\mathbf{K g})\end{array}$ & $\begin{array}{l}\text { Volume Beli } \\
(\mathbf{K g})\end{array}$ & $\begin{array}{c}\text { Harga Jual } \\
(\mathbf{R p} / \mathbf{K g})\end{array}$ & $\begin{array}{l}\text { Harga Beli } \\
(\mathbf{R p} / \mathbf{K g})\end{array}$ \\
\hline Pedagang Besar & 210 & 110 & 20.400 & 16.900 \\
\hline Pedagang Pengecer & 41,75 & 32 & 21.900 & 20.200 \\
\hline
\end{tabular}

Berdasarkan tabel 9 didapatkan bahwa untuk komoditi bawang merah volume jual rata rata sebesar $210 \mathrm{~kg}$ dengan sampel pedagang sebanyak 20 orang sampel pedagang besar dan volume jual rata - rata pedagang pengecer sebesar $41,75 \mathrm{~kg}$ untuk 5 orang sampel pedagang pengecer. Selanjutnya pada volume beli rata - rata pedagang besar sebesar $110 \mathrm{~kg}$ dari 20 orang 
sampel yang diteliti dan volume beli rata - rata $32 \mathrm{~kg}$ dari 5 orang sampel yang diteliti. Untuk rata - rata harga jual pada pedagang besar sebesar Rp. $20.400 / \mathrm{kg}$ dengan jumlah sampel 20 orang, dan untuk rata - rata harga jual pada pedagang pengecer sebesar Rp. $21.900 / \mathrm{kg}$ dari jumlah sampel 5 orang. Dan untuk rata - rata harga beli pada pedagang pengecer sebesar Rp. $16.900 / \mathrm{kg}$ dengan jumlah sampel 20 orang, dan untuk rata - rata harga beli pada pedagang pengecer sebesar Rp. $20.200 / \mathrm{kg}$ dari jumlah sampel 5 orang.

Tabel 10. Kontigensi Saluran Distribusi dan Penetapan Harga Cabai Merah pada Pedagang Besar dan Pedagang Pengecer

\begin{tabular}{|c|c|c|c|c|}
\hline \multirow[b]{2}{*}{ Saluran Distribusi } & \multicolumn{4}{|c|}{ Penetapan Harga } \\
\hline & $\begin{array}{c}\text { Volume Jual } \\
(\mathrm{Kg})\end{array}$ & $\begin{array}{l}\text { Volume Beli } \\
\text { (Kg) }\end{array}$ & $\begin{array}{c}\text { Harga Jual } \\
\text { (Rp/Kg) }\end{array}$ & $\begin{array}{c}\text { Harga Beli } \\
\text { (Rp/Kg) }\end{array}$ \\
\hline Pedagang Besar & 370 & 200 & 40.400 & 37.000 \\
\hline Pedagang Pengecer & 49 & 36.75 & 16.560 & 39.400 \\
\hline
\end{tabular}

Berdasarkan tabel 10 didapatkan bahwa untuk komoditi cabai merah volume jual rata rata sebesar $370 \mathrm{~kg}$ dengan sampel pedagang sebanyak 20 orang sampel pedagang besar dan volume jual rata - rata pedagang pengecer sebesar $49 \mathrm{~kg}$ untuk 5 orang sampel pedagang pengecer. Selanjutnya pada volume beli rata - rata pedagang besar sebesar $200 \mathrm{~kg}$ dari 20 orang sampel yang diteliti dan volume beli rata - rata $36,75 \mathrm{~kg}$ dari 5 orang sampel yang diteliti. Untuk rata - rata harga jual pada pedagang besar sebesar Rp. $40.400 / \mathrm{kg}$ dengan jumlah sampel 20 orang, dan untuk rata - rata harga jual pada pedagang pengecer sebesar Rp. $16.560 / \mathrm{kg}$ dari jumlah sampel 5 orang. Dan untuk rata - rata harga beli pada pedagang pengecer sebesar Rp. $37.000 / \mathrm{kg}$ dengan jumlah sampel 20 orang, dan untuk rata - rata harga beli pada pedagang pengecer sebesar Rp. $39.400 / \mathrm{kg}$ dari jumlah sampel 5 orang.

Tabel 11. Kontigensi Saluran Distribusi dan Penetapan Harga Tomat pada Pedagang Besar dan Pedagang Pengecer

\begin{tabular}{lrrrr}
\hline \multirow{2}{*}{ Saluran Distribusi } & \multicolumn{4}{c}{ Penetapan Harga } \\
\cline { 2 - 5 } & \multicolumn{1}{c}{$\begin{array}{c}\text { Volume Jual } \\
(\mathbf{K g})\end{array}$} & $\begin{array}{c}\text { Volume Beli } \\
(\mathbf{K g})\end{array}$ & $\begin{array}{c}\text { Harga Jual } \\
(\mathbf{R p} / \mathbf{K g})\end{array}$ & $\begin{array}{c}\text { Harga Beli } \\
(\mathbf{R p} / \mathbf{K g})\end{array}$ \\
\hline Pedagang Besar & 180 & 70 & 10.400 & 7000 \\
Pedagang Pengecer & 35,75 & 25 & 11.300 & 9.550 \\
\hline
\end{tabular}

Berdasarkan tabel 11 didapatkan bahwa untuk komoditi tomat volume jual rata - rata sebesar $180 \mathrm{~kg}$ dengan sampel pedagang sebanyak 20 orang sampel pedagang besar dan volume jual rata - rata pedagang pengecer sebesar $35,75 \mathrm{~kg}$ untuk 5 orang sampel pedagang pengecer. Selanjutnya pada volume beli rata - rata pedagang besar sebesar $70 \mathrm{~kg}$ dari 20 orang sampel yang diteliti dan volume beli rata - rata $25 \mathrm{~kg}$ dari 5 orang sampel yang diteliti. Untuk rata rata harga jual pada pedagang besar sebesar Rp. 10.400 /kg dengan jumlah sampel 20 orang, dan untuk rata - rata harga jual pada pedagang pengecer sebesar Rp. $11.300 / \mathrm{kg}$ dari jumlah sampel 5 orang. Dan untuk rata - rata harga beli pada pedagang pengecer sebesar Rp. $7.000 / \mathrm{kg}$ dengan jumlah sampel 20 orang, dan untuk rata - rata harga beli sebesar Rp. $9.550 / \mathrm{kg}$ dari jumlah sampel 5 orang pada pedagang pengecer.

Berdasarkan ke tiga tabel di atas dapat dilihat bahwa contigency coefficient ( $\mathrm{r}$ ) memiliki hasil 0,707 yang berarti saluran distribusi memiliki keterkaitan yang kuat dengan penetapan 
harga sayuran pada pedagang besar dan pedagang pengecer di Kota Banda Aceh,yang di uji analisis Chi Square dengan menggunakan SPSS. Dan karena nilai r bernilai positif, maka keterkaitan antara saluran distribusi dengan penetapan harga sayuran sangat erat. Artinya semakin besar (panjang) saluran distribusi, maka akan semakin mahal harga pada tiap masingmasing pedagang.

\section{Jenis Saluran}

Adapun jenis saluran distribusi menurut Kotler dan Keller (2007), jumlah tingkat saluran distribusi dibagi dalam empat jalur yang dapat dipakai produsen dalam menyalurkan produknya, yaitu :

1. Saluran nol - tingkat

Disebut saluran pemasaran langsung, terdiri dari produsen yang langsung menjual kepada konsumen akhir.

2. Saluran satu - tingkat

Mempunyai satu perantara penjual,seperti pengencer.

3. Saluran dua - tingkat

Mempunyai dua perantara. Dalam pasar barang konsumsi, mereka umumnya adalah pedagang besar dan pengecer.

4. Saluran tiga - tingkat

Mempunyai tiga perantara, misalnya pedagang besar menjual ke pemborong, yang akan menjualnya beberapa pedagang kecil.

Berdasarkan hasil penelitian dilakukan di pasar lambaro dan pasar peunayong untuk jenis komoditi bawang,tomat, dan cabai merah didapatkan jenis saluran yang terbentuk yaitu jenis saluran tingkat dua yang di mulai dari produsen - pedagang besar - pedagang pengecer konsumen akhir. Masing - masing tingkat saluran distribusi memiliki peran dalam hal penetapan harga.

Dari hasil penelitian diperoleh sampel pedagang besar sebanyak 5 orang dengan masing masing mempunyai volume yang berbeda dan mengeluarkan biaya pemasaran yang berbeda beda juga seperti ongkos, gaji, tempat (lapak), retribusi, dan kemasan. Untuk komoditi bawang merah rata - rata mempunyai volume beli sebanyak $210 \mathrm{~kg} / \mathrm{hari}$ dan volume jual sebanyak 110 $\mathrm{kg} / \mathrm{hari}$. Untuk komoditi cabai merah rata - rata mempunyai volume beli $370 \mathrm{~kg} / \mathrm{hari}$ dan volume juals sebanyak $200 \mathrm{~kg} / \mathrm{hari}$. Dan untuk komoditi tomat rata - rata mempunyai volume beli sebanyak $180 \mathrm{~kg} /$ hari dan volume jual sebanyak $70 \mathrm{~kg} /$ hari. Dan total rata - rata biaya pemasaran yg keluarkan sebesar Rp. 46.307 .200 per tahun.

Kemudian untuk pedagang pengecer diperoleh sampel sebanyak 25 orang dengan masing - masing mempunyai volume yang berbeda dan mengeluarkan biaya pemasaran yang berbeda - beda juga seperti ongkos, gaji, tempat (lapak), retribusi, dan kemasan. Untuk komoditi bawang merah rata - rata mempunyai volume beli sebanyak $41,75 \mathrm{~kg} / \mathrm{hari}$ dan volume jual 32 $\mathrm{kg} /$ hari. Untuk komoditi cabai merah rata - rata mempunyai volume sebanyak beli $49 \mathrm{~kg} / \mathrm{hari}$ dan volume jual sebanyak $36,75 \mathrm{~kg} / \mathrm{hari}$. Dan untuk komoditi tomat rata - rata mempunyai volume beli sebanyak 35,75 kg/hari dan volume jual sebnyak $25 \mathrm{~kg} / \mathrm{hari}$. Dan total rata - rata biaya pemasaran yg keluarkan sebesar Rp. 41.250.000per tahun.

Adapun perbedaan dalam penetapan harga pada masing - masing tingkat saluran distribusi, menurut Fandy tjiptono (2008) tujuan penetapan harga pada dasarnya terdapat empat jenis tujuan penetapan harga, yaitu :

a. Tujuan Beroreintasi Pada Laba

Asumsi teori ekonomi klasik yang menyatakan bahwa setiap perusahaan selalu memilih harga yang dapat menghasilkan lanapaling tinggi. Tujuan ini dikenal dengan istilah maksimalisasi laba. Dalam era persaingan global yang kondisinya sangat kompleks 
maksimalisasi laba sangat sulit dicapai, karena sukar sekali untuk dapat memperkirakan secara akurat jumlah penjualan yang dapat dicapai pada tingkat harga tertentu . dengan demikian, tidak munkin seatu perusahaan dapat mengetahui secara pasti tingkat harga yang dapat menghasilkan laba maksimum.

b. Tujuan Beroreintasi Pada Volume

Selain tujuan beroreintasi pada laba, ada pula perusahaan yang menetapkan harganya berdasakan tujuan yang beroreintasi pada volume tertentu atau yang biasa dikenal dengan istilah volume pricing objectives. Harga ditetapkan sedimikian rupa agar dapat mencapai target volume penjualan. Tujuan ini banyak diterapkan oleh perusahaan penerbangan, lembaga pendidikan pengusaha bioskop dan pemilik bisnis pertunjukan lainya. Bagi sebuah perusahaan penerbangan, biaya penerbangan untuk satu pesawat terisi penuh maupun yang hanya terisi separuh tidak banyak berbeda. Oleh karena itu, banyak perushaan penerbangan yang berupaya memberikan insentif berupa harga special agar dapat meminimalisasi jumlah kursi yang tidak terisi.

c. Tujuan Beroreintasi Pada citra

Citra (image) suatu perusahaan dapat dibentuk melalui strategi penetapan harga. Perusahaan dapat menerapkan harga tinggi untuk membentuk atau mempertahankan citra prestisius. Sementara itu harga rendah dapat digunakan untuk membentuk citra nilai tertentu (image of value), missal dengan memberikan jaminan bahwa harganya merupakan harga yang terendah disuatu wilayah tertentu. Pada hakikatnyaa, naik penetapan harga tinggi mapun rendah bertujuan untuk meningkatkan persepsi konsumen terhadap keseluruhanbauran produk yang ditawarkan perusahaan.

d. Tujuan Stabilisasi Harga

Dalam pasar yang konsumennya sangat sensitive terhadap harga, bila suatu perusahaan menurunkan harganya, maka para pesaingnya harus menurunkan pula harga mereka. Kondisi seperti ini yang mendasari terbentuknya tujuan stabilisasi dilakukan dengan jalan menetapkan harga untuk menetapkan harga untuk mempertahankan hubungan yang stabil antara harga suatu perusahaan dan harga pemimpin industri (industy leader).

e. Tujuan tujuan lainnya

Harga dapat pula ditetapkan dengan tujuan mencegah masuknya pesaing, mempertahankan loyalitas pelanggan, mendukung penjualan ulang atau menghindari campur tangan pemerintah. Hasil Analisis Uji Chi Square

Berdasarkan hasil penelitian yang dilakukan menggunakan uji chi square dengan aplikasi SPSS, maka didapatkan hasil seperti pada Tabel 12 sebagai berikut:

Tabel 12. Hasil Uji Chi Square

\begin{tabular}{ccc}
\hline No. & Hasil Pengujian & Nilai \\
\hline 1. & $\mathrm{X}^{2}$ hitung & 2,000 \\
2. & $\mathrm{X}^{2}$ tabel & 7,879 \\
3. & $\mathrm{~A}$ & 0,05 \\
4. & $\mathrm{p}_{\text {value }}$ & 0,157 \\
5. & Contigency coefficient $(\mathrm{r})$ & 0,707 \\
\hline
\end{tabular}

Sumber: Data Primer, 2017 (Diolah)

Berdasarkan Tabel 12 didapatkan bahwa $X^{2}{ }_{\text {hitung }}<X^{2}$ tabel dan $\alpha \geq$ palue yang menunjukkan $\mathrm{H}_{a}$ diterima dan $\mathrm{H}_{0}$ ditolak, artinya saluran distribusi berpengaruh tidak nyata (non signifikan) pada pedagang besar dan pedagang pengecer di Kota Banda Aceh. Hasil penelitian ini menunjukkan bahwa penetapan harga tidak sepenuhnya tergantung pada saluran distribusi, penetapan harga juga ditentukan oleh kualitas barang, tempat penjualan, dan biaya - biaya yang di tanggung oleh pedagang besar dan pedagang pengecer. 
Hasil wawancara dengan pedagang besar dan pedagang pengecer penjual sayur - sayuran ( cabai merah, bawang merah, dan tomat ) tergantung pada volume penjualan dan konsumen yang di layani. Untuk volume penjualan yang banyak ada pengurangan harga jual antara 10 $20 \%$ dari harga yang telah di tetapkan. Hal tersebut sesuai dengan pendapat Winardi (1992) yang menyatakan bahwa proses dimana penjual memastikan, me - aktifasi, dan memuaskan kebutuhan atau keinginan penjual dan konsumen yang berkelanjutan dan yang menguntungkan kedua belah pihak. Berdasarkan Tabel 12 dapat dilihat bahwa contigency coefficient ( $\mathrm{r}$ ) memiliki hasil 0,707 yang berarti saluran distribusi memiliki keterkaitan yang kuat dengan penetapan harga sayuran pada pedagang besar dan pedagang pengecer di Kota Banda Aceh. Dan karen nilai $r$ bernilai positif, maka keterkaitan antara saluran distribusi dengan penetapan harga sayuran. Artinya semakin besar (panjang) saluran distribusi, maka akan semakin mahal harga pada tiap masing-masing pedagang.

\section{KESIMPULAN}

Adapun kesimpulan yang dapat diberikan pada penelitian ini adalah:

Pedagang pengecer sebaiknya untuk memperbesar usaha dagangannya ( menjadi pedagang besar ) hal ini dikarenakan pendapatan pedagang besar lebih besar dan lebih menguntungkan.

Untuk pedagang besar sebaiknya stok sayuran untuk lebih di tingkatkan jumlah nya dari jumlah sebelumnya, agar memudahkan pedagang lain khusus nya pedagang pengecer untuk mendapatkan sayuran yang akan di jual banyak.

\section{DAFTAR PUSTAKA}

Anggraini, Lupitasari. 2014. Pengaruh Biaya Distribusi Terhadap Volume Penjualan. PT. Salama Nusantara . Universitas Negeri. Jogjakarta.

Boyd, Harper W., Jr. \& Orville C. Walker, Jr. 1992. Marketing Management:

A Strategic Approach. Illinois: Richard D. Irwin, Inc.

Belshaw, Cyril S. 1981. Tukar-Menukar Tradisional dan Pasar Modern. Jakarta: PT Gramedia. Djaslim Saladin. 1996. 2003. Unsur-Unsur Inti Pemasaran Dan Manajemen Pemasaran. Bandung: Mandar Maju.

Eko Putra. 2013. Pengaruh Biaya Distribusi Terhadap Volume Penjualan Minyak Kelapa Sawit

$(C P O)$. Jurnal Apresiasi Ekonomi. Vol 5,No. 1 PT. Grasindo Minang Plantation Barat.

Keegan, Warren J. 2005. Manajemen Pemasaran Global, edisi keenam, PT. Indeks, Jakarta. Kotler, Philip. 1997. Manajemen Pemasaran. Jakarta: Prenhallindo.

Kotler, Armstrong. 1996. Principles of Marketing . 7th. Ed. New York: Prentice-Hall Inc.

Machfoedz, Mhmud. 2005. Pengantar Pemasaran Modern. Yogyakarta : Upp Amp Ykppn.

Maduretno Widowati. 2010. Pengaruh Harga,Promosi,Merk Terhadap Penjualan barang Pharmasidi. Fokus Ekonomi. Vol 5,No.1 . PT. Anugerah Pharmindo Lestari.

Mantra, I.B. 2004. Demografi Umum. Pustaka Pelajar. Yogyakarta

Nazir. Moh Ph. D. 2005. Metode Penelitian. Bogor: Ghalia Indonesia. 
Nitisemito, Alex S. 1993. Manajemen Personalia - Manajemen Sumber Daya Manusia. Jakarta: Ghalia.

Nitisemito, A, Dale, 1993. Manajemen Personalia Sumber Daya Manusia. Ghalia Indonesia.Jakarta:

William J. Stanton. 2000. Dasar-dasar Pemasara, Edisi ke tujuh. Jakarta: Erlangga. Winardi. 1992. Strategi Pemasaran. Cetakan ketiga. Penerbit Mandar Maju. Bandung Sugiyono, 2008. Metode Penelitian Bisnis. Cetakan Kedua belas. Bandung: Alfabeta.

Swasta, Basu DH dan Irawan. M.B.A. 1986. Manajemen Pemasaran Modern. Yogyakarta: Liberty.

Tjiptono, Fandy. 2008. Strategi Pemasaran. Yogyakarta: Penerbit Andi Offset. 